Military Technical College Kobry El-Kobbah, Cairo, Egypt

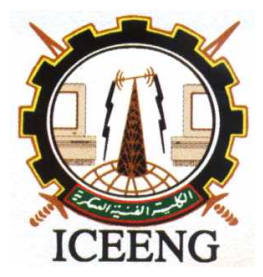

\author{
$6^{\text {th }}$ International Conference \\ on Electrical Engineering \\ ICEENG 2008
}

\title{
Modeling, simulation and implementation of four-switch, brushless DC motor drive based on switching function concept
}

\author{
By
}

Abolfazl Halvaei Niasar* Hassan Moghbeli** Abolfazl Vahedi****

\section{Abstract:}

In this paper, a functional simulation model for a Four-Switch, Three-Phase Inverter (FSTPI) Brushless DC (BLDC) motor using switching function concept is presented and the actual implementation of the model is proposed with the help of Matlab/Simulink. In this model an entire BLDC motor drive including power conversion unit, BLDC motor, and speed control system, is investigated. The proposed model is exact and easy for implementation. Using this concept, it is possible to show he detailed electrical variables, such as phase current, line and phase voltages and diode and switch currents. Duo to problems caused of eliminating two power switches, Direct Current Control (DCC) method is carried out in the simulations. The validity of the proposed model is validated by simulation and experimental results.

* Iran University of Science \& Technology, Tehran, IRAN A\&M University at Qatar, Doha, Qatar Technology, Tehran, IRAN

** Department of Mathematics, Texas A\&M University at Qatar, Doha, Qatar Technology,

*** Iran University of Science \& Technology, Tehran, IRAN A\&M University at Qatar, Doha, Qatar Technology, Tehran, IRAN 


\section{MODELING OF FSTPI-BLDC MOTOR DRIVE BASED ON SWITCHING FUNCTION CONCEPT:}

Prediction of motor performance is necessary for the evaluation characteristics of motor designs and motor modeling. Simulation design is a preferred method in motor designing compared to building motor prototypes that is more costly and needs longer time. Effective modeling and simulation of such systems require a software tool that can handle all these functions in an integrated environment. Available simulation softwares for electronic circuits or dynamic systems can be classified into two main categories: (1) circuit simulation programs such as Spice-based, EMTP, Saber (2) equation solver programs such as SIMNON. These programs are not designed specifically for power electronic systems so that the users have to develop their own models to fulfill their needs. It has shown that the switching function concept is a powerful tool in understanding and optimizing the

performance of the static power inverters. Using the switching function concept, the power conversion circuits can be modeled according to their functions, rather than circuit topologies. Therefore, it can achieve simplification of the overall power conversion functions and also allow for the development of analytical concepts that are applicable to families of converters instead of individual ones. Fig. 1 shows the configuration of a fourswitch BLDC motor drive that the direct phase current (DPC) control method is employed for current regulation.

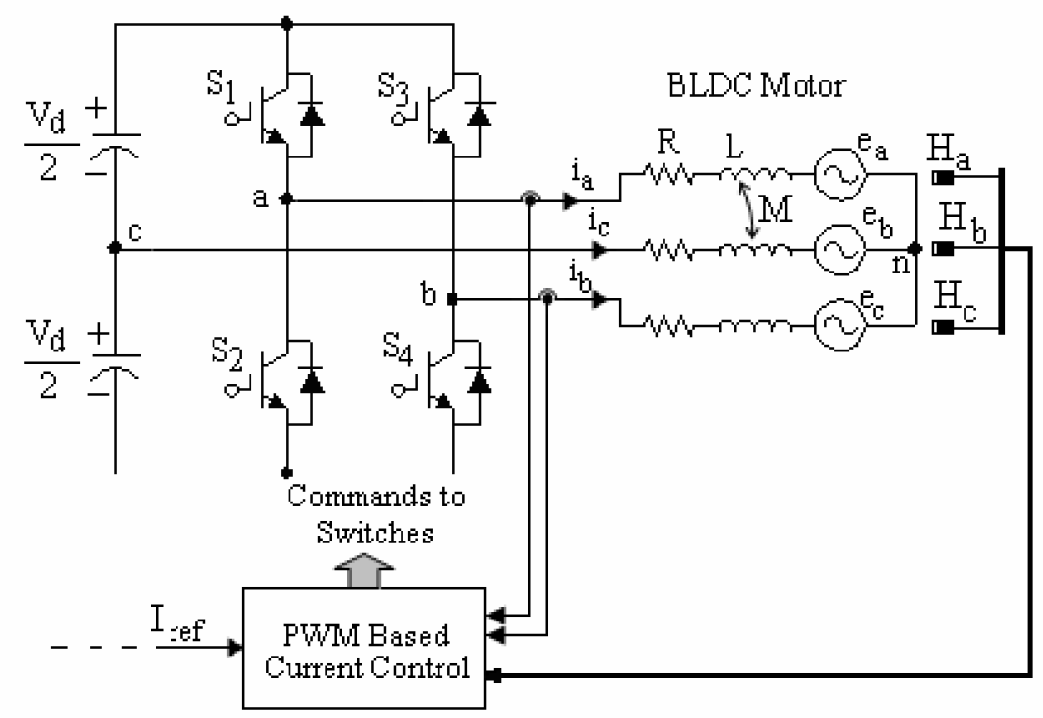

Figure (1): Four-switch inverter for 3-phase BLDC motor using DCC 
Fig. 2 shows the overall block diagram of the developed model for a four-switch inverter, three-phase BLDC motor drive that shown in Fig.3. It contains four functional blocks. In Speed Control block, speed is regulated and reference current is generated. In Current Control block, currents of phase A and B are regulated via two independent hysteresis controllers. In Power Inverter block, using switching functions Da and Db that are duty cycles of power switches, phase terminal voltages of BLDC motor is generated. The last block is BLDC Motor that all mathematical equations of BLDC motor is implemented. The implementation of the BLDC Motor block in Matlab / Simulink environment is shown in Fig. 3.

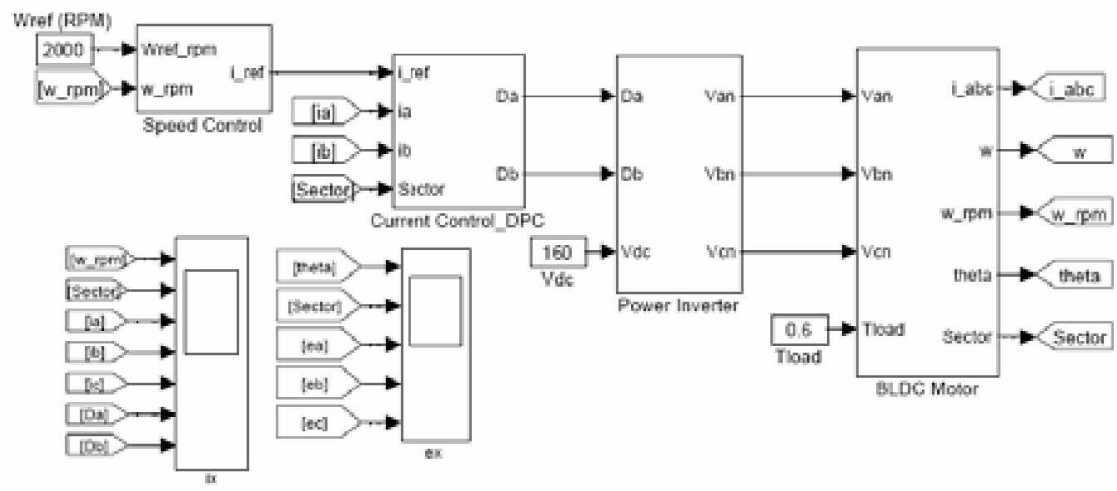

Figure (2): Implementation of switching function concept based model for the four-switch inverter, BLDC motor drive in Matlab/Simulink

\section{Simulation:}

Fig. 4 shows the phase current waveforms when the conventional DC-bus current control method is used for current regulation. As shown, due to effect of back-EMF voltage of phase $\mathrm{C}$, the phase currents are disturbed in two modes 2 and 5. Also, Fig. 5 shows the phase current waveforms when the direct phase current (DPC) control method is employed. It can be seen that the phase currents are exactly rectangular. Moreover, the developed model can show the problems of four-switch BLDC motor drive performance at high-speed ranges. Fig. 6 shows the drive performance at high-speed range. 


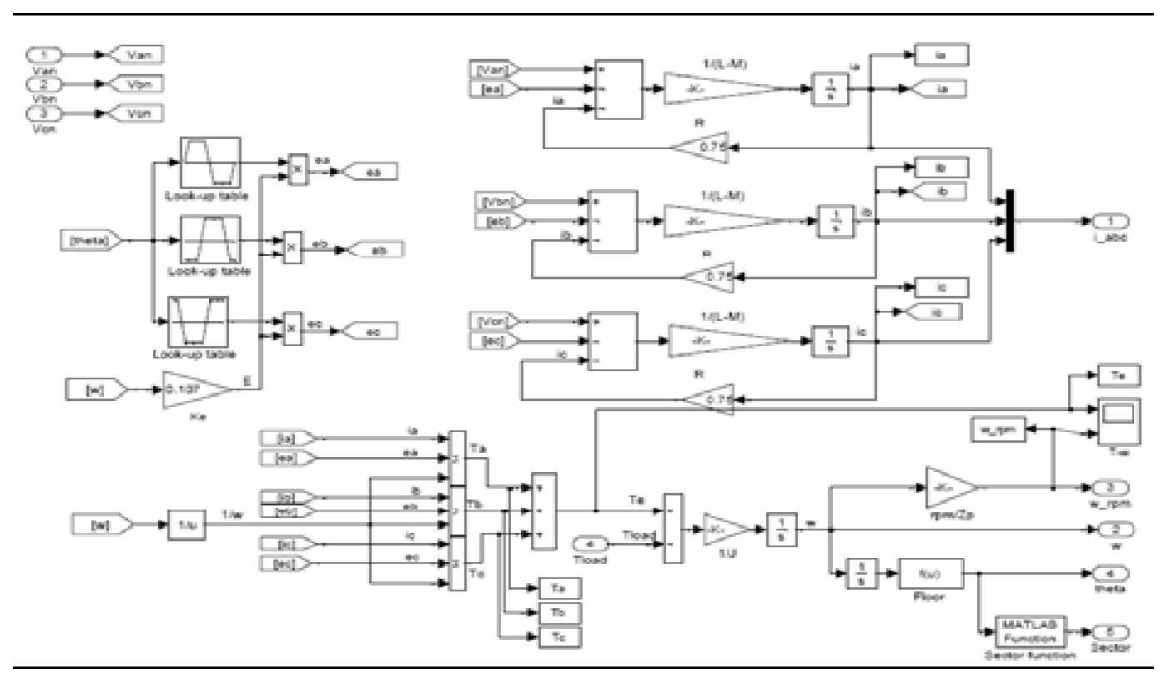

Figure (3): Implementation of the BLDC Motor block in Matlab/Simulink
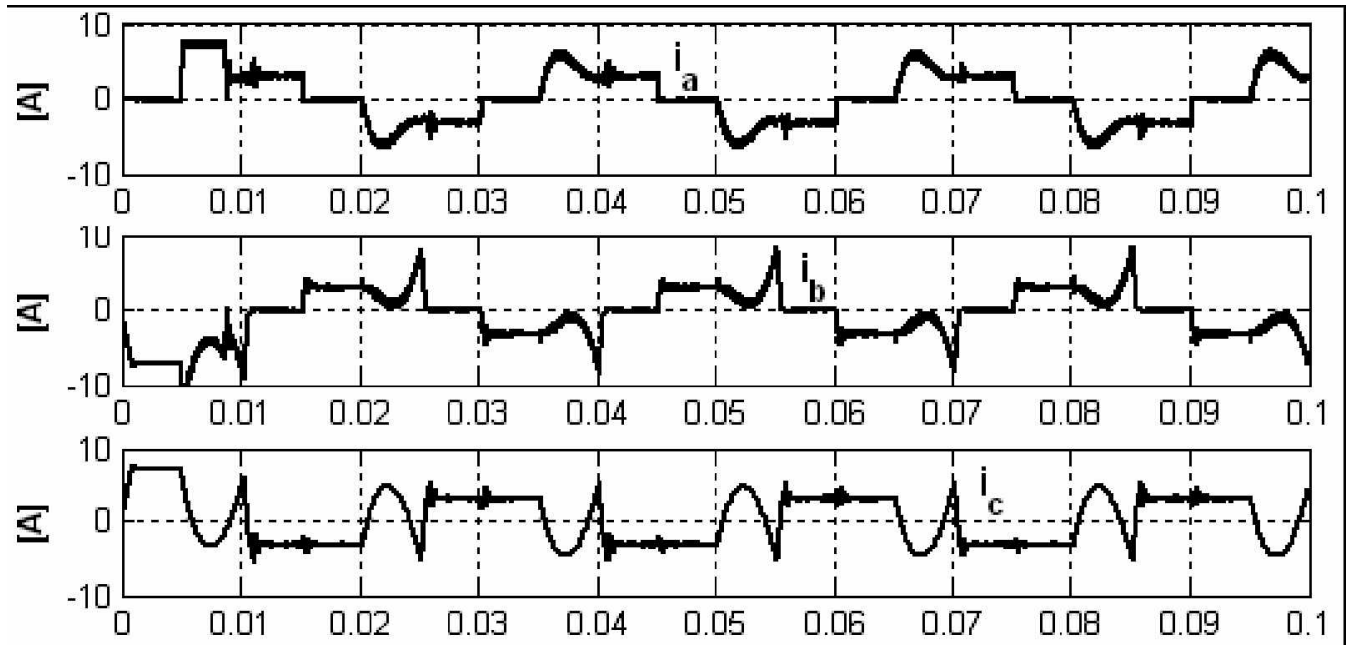

Figure (4): Current waveform using conventional DC-bus control method 


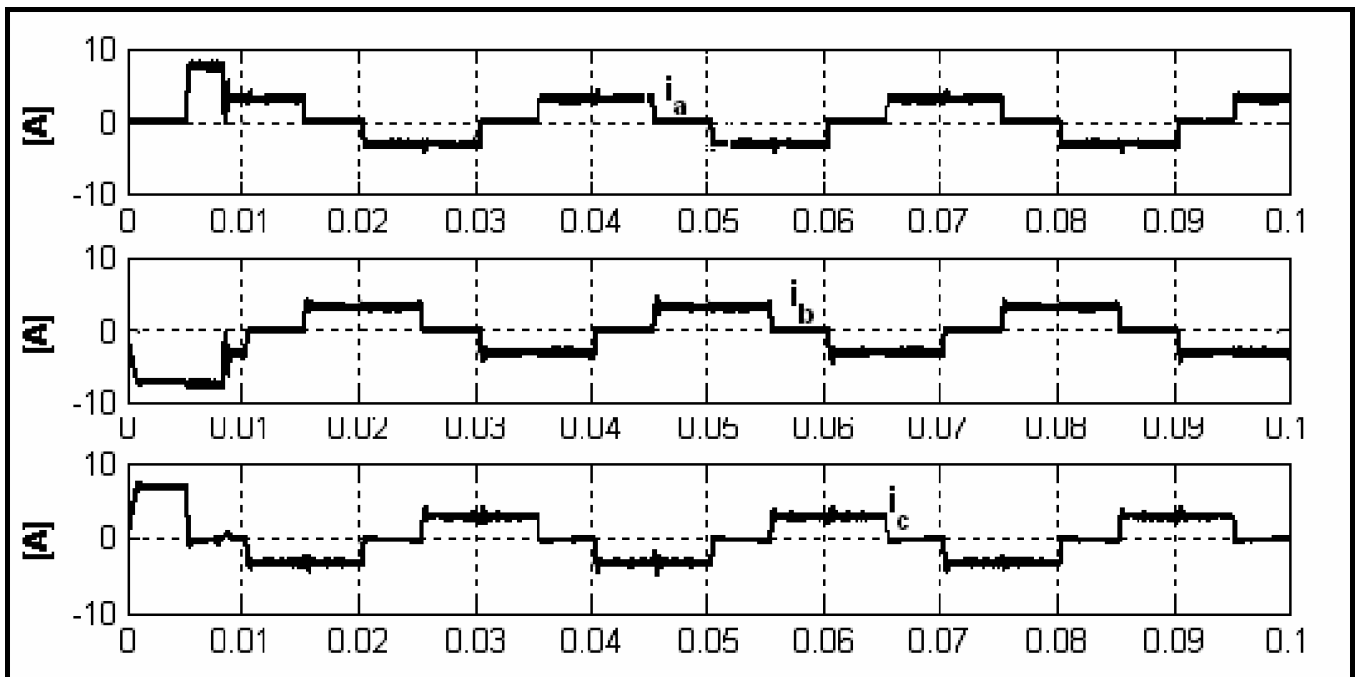

Figure (5): Current waveform using DPC control method at speed 2000 rpm

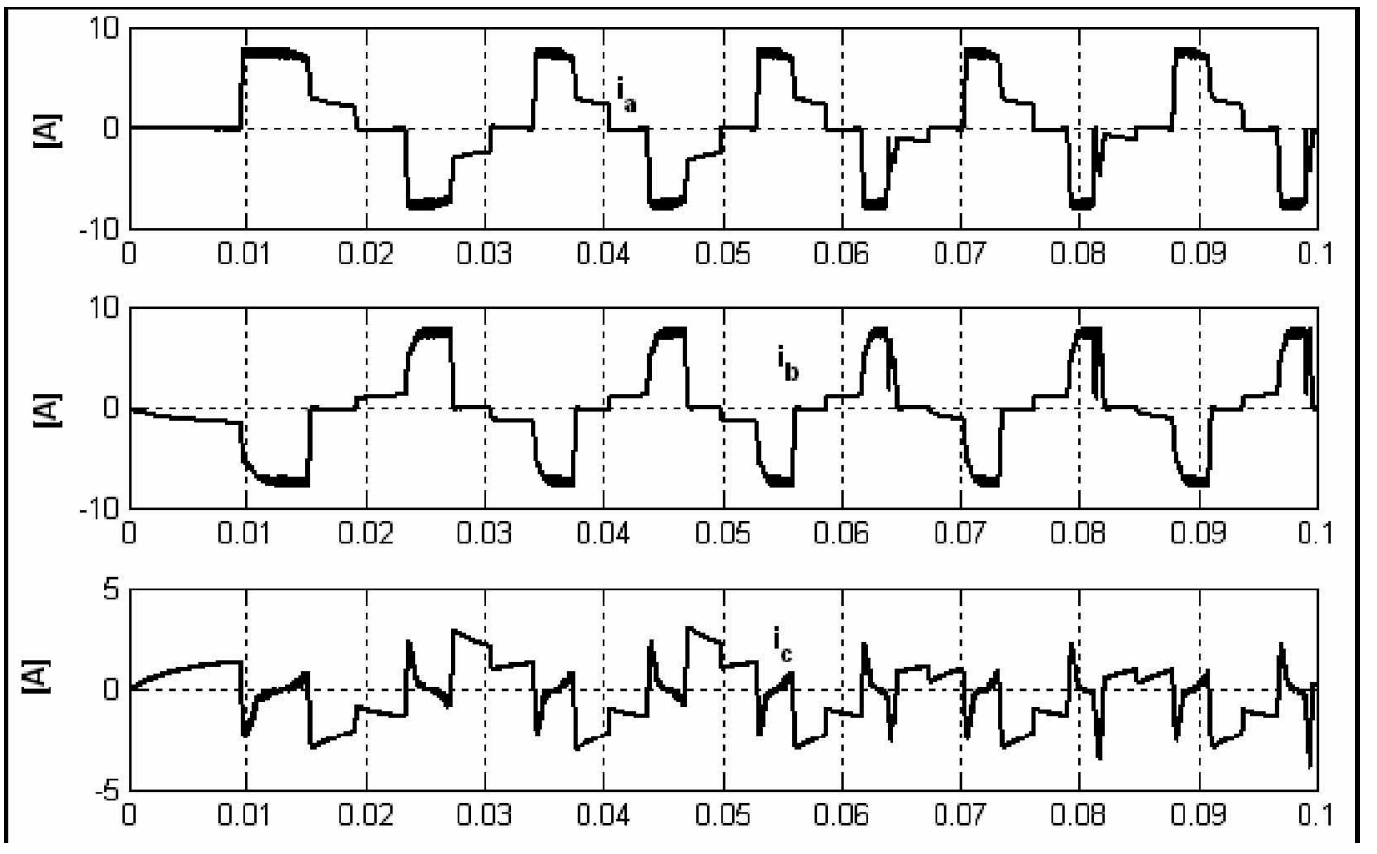

Figure (6): Current waveform using DPC control method at speed $3500 \mathrm{rpm}$ 


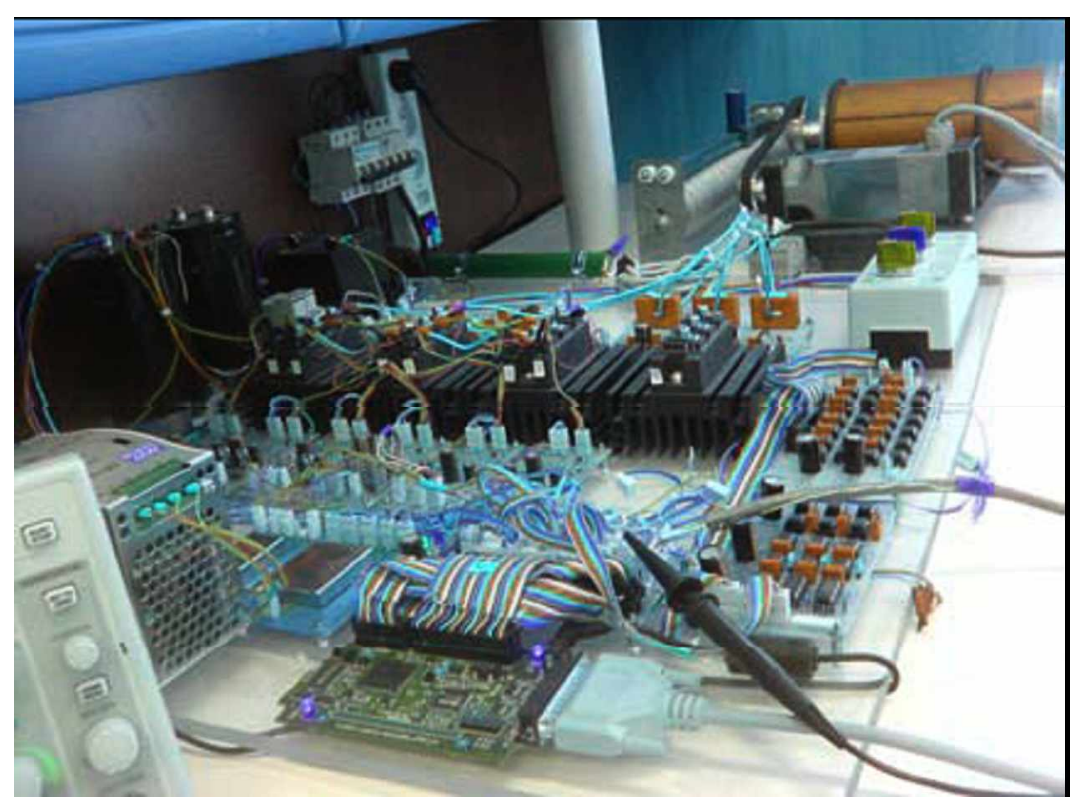

Figure (7): Experimental Four-Switch B,LDC motor drive system

\section{Implementation:}

For validation of the proposed modeling approach, the simulation results are compared with experimental results. Fig. 7 shows the experimental setup that consists of a $1 \mathrm{~kW} / 3500 \mathrm{rpm}$ BLDC motor drive loaded with $180 \mathrm{~V}$ DC generator. The IGBTs are used as inverter switches where the switching frequency is $15 \mathrm{kHz}$. Fig. 8 and Fig. 9 show the current waveforms with conventional DC-bus current regulation and with DPC control method respectively. 
Proceedings of the $\boldsymbol{6}^{\text {th }}$ ICEENG Conference, 27-29 May, 2008

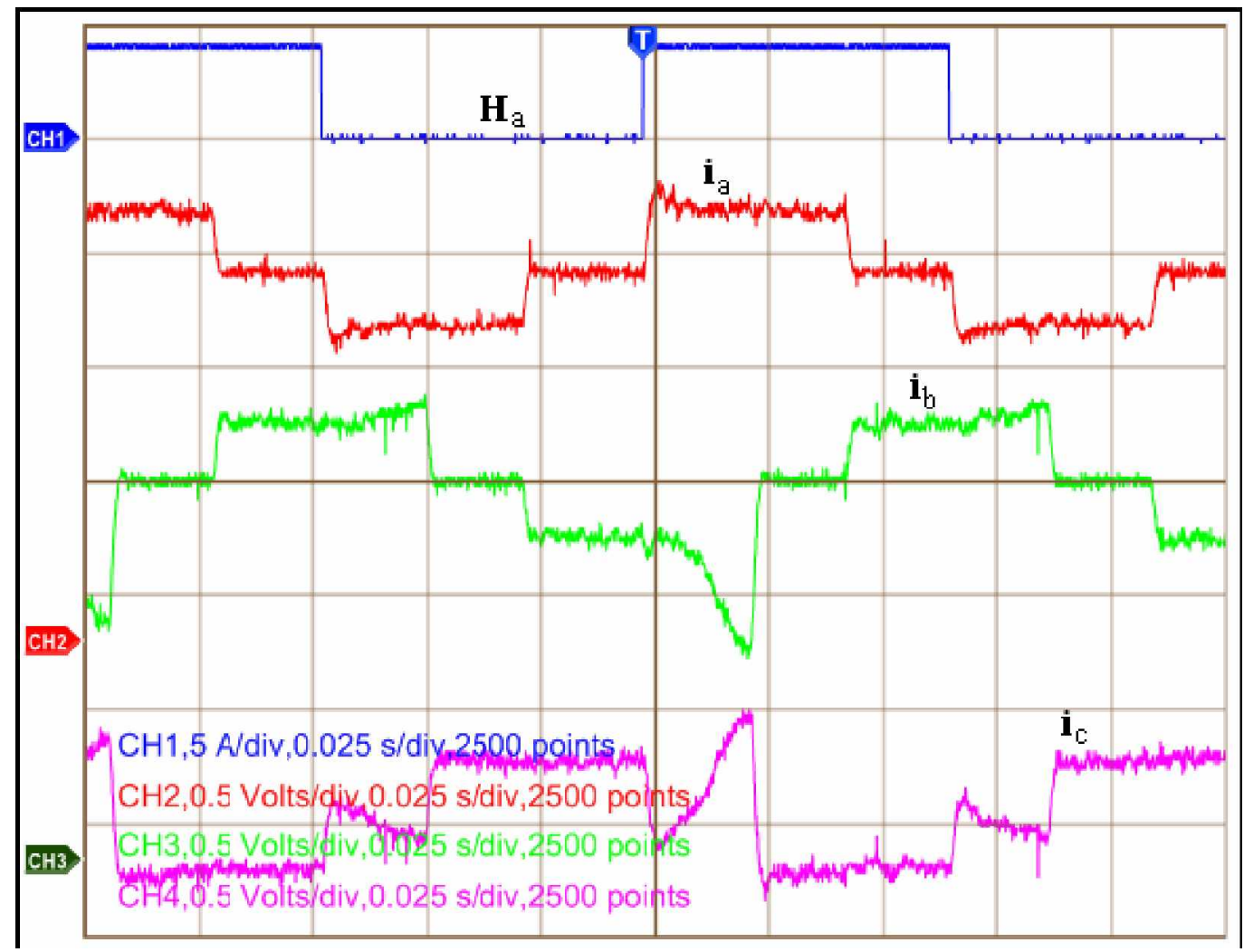

Figure (8): Phase current waveforms and hall sensor Ha with conventional DC-bus control method 


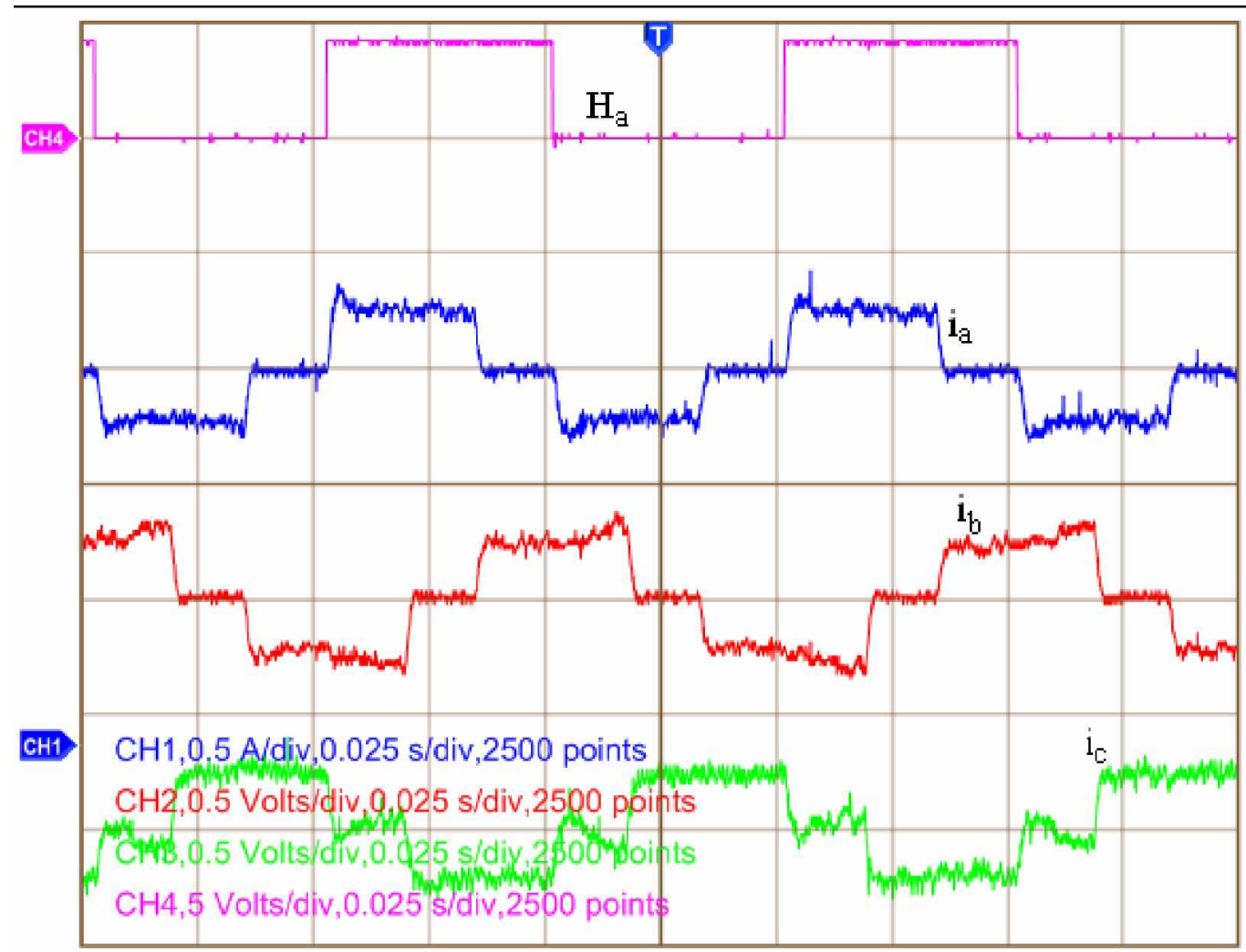

Figure (9): Phase current waveforms and hall sensor Ha using DPC control method

\section{Conclusions:}

In this paper, at first the different modeling methods for modeling of the BLDC motor drive system were explored. Linear modeling is not an effective method to estimate transient state and motor's nonlinearity. Field oriented based method is not accurate method and needs to complex mathematics. Numerical modeling methods have too complex calculations and are often used for design the motor. Then we used switching function concept (SFC). The SFC based developed model has the major following advantages: (1) Simplification of the power conversion circuit (2) Providing an easy-todesign tool for design (3) Extending to other systems due to its modular structure. The performance of the proposed FSTPI-BLDC drive can be enhanced by considering the nonideal back-EMF voltage waveforms, torque ripple due to commutation and cogging effect. The experimental results confirmed the developed model and the simulation results. 